\title{
Volume of Distribution for Dosing Interval Normalized by Weight
}

National Cancer Institute

\section{Source}

National Cancer Institute. Volume of Distribution for Dosing Interval Normalized by

Weight. NCl Thesaurus. Code C111372.

The volume of distribution associated with the terminal slope following intravascular administration, calculated using AUCTAU, divided by the weight. 